A publication of the Muma College of Business | University of South Florida

\begin{tabular}{lll}
\hline Volume 6 & Number 20 & 20 JULY 2021 \\
\hline
\end{tabular}

CHAD ANAST, MICHAEL MCCLENDON II, RUSSELL NELSON, MELISSA SMITH, STACIE VARNEY

\title{
ROCK, PAPER, CONCRETE... 1
}

Concrete has evolved significantly over the last 40 years, so why is the time and attendance of the people who pour it stuck in the prior century?

"We're a $\$ 500$ million construction company and we still use paper to sign in!". While attempting to relax on the back porch of his plush home with his feet up, Max Murray, CFO of MAVNS

Concrete Construction, reflected on the message he conveyed to his team in an earlier meeting. This polar realization was about as cold as the beer he was opening and almost just as much needed. The recent examination of MAVNS' processes made him cringe with apprehension; their sign-in methods were archaic at best and out of sync with current technologies. His frustration quickly shifted as he took another sip - "how do we improve our processes and get buy-in from management so we can ultimately improve profitability?"

Murray witnessed MAVNS' struggle through electronic onboarding implementation, I-9s, and an extensive project management software which most districts resisted, further undermining company esprit de corps. Max was well aware of the complexity of these issues, in addition to the positive effect a more accurate time-keeping method for tracking hours performed per job site would have on the business's bottom-line. The reduction of risk associated with fraudulent documentation was only the tip of the iceberg, as other obvious opportunities existed because of this technological deficiency.

MAVNS Concrete Construction still utilized paper sign-in sheets (see Exhibit 1) as the time-keeping records method to account for their job-specific payroll. With over 4,000 employees (see Exhibit 2), 1,800 in the field including 800 in Florida alone, maintaining accurate time records was crucial. A typical project had 40 - 100 employees onsite. Max recalled witnessing this debacle firsthand, reflecting on seeing this manual process in action, accompanied by long employee wait lines, congested job trailers, and disgruntled employees; not to mention tales of "time fudging" via other employees signing their peers in and out inappropriately.

Could Murray usher MAVNS out of the industrial dark ages? What approach(s) would promote optimal accuracy and efficiency? Customizing existing software? Adopting an entirely new system and plunging forward into the future? Understanding the costs, benefits, competitive advantages, and potential risks would prove pivotal in Murray's decision.

${ }^{1}$ Copyright (C) 2021, Chad Anast, Michael McClendon II, Russell Nelson, Melissa Smith, Stacie Varney. This case was prepared for the purpose of class discussion, and not to illustrate the effective or ineffective handling of an administrative situation. Names and some information have been disguised. This case is published under a Creative Commons BY-NC license. Permission is granted to copy and distribute this case for non-commercial purposes, in both printed and electronic formats. 
ANAST, MCCLENDON II, NELSON, SMITH, VARNEY

\section{The Concrete Industry}

\section{Concrete Specialty Contractors}

There were approximately forty specific trades within the construction industry (Ridell, 2017). Specialty contractors, like MAVNS Concrete Construction, were hired for their specialized expertise in construction. The specialty contractors were the most knowledgeable and experienced in their specific trade, including the code requirements, government regulations, and depth of products. The specialty contractors were hired by the general contractor to complete a portion of the construction project.

The US market for Concrete Contractors was $\$ 59$ billion (IBIS World, 2020) for 2019. The industry saw an average growth of $4.6 \%$ over the last five years. The concrete industry has vast reach; it literally provides the foundation for virtually all industries. This diverse business can weather variability in any one customer segment. The competition that MAVNS faced was tough - as the industry did not have one company with a market share greater than $5 \%$.

MAVNS had been able to stand out among its competition with its primary goal to build the highestperforming structures possible with the least amount of initial and operating cost in the shortest amount of time.

\section{Tight Budgets}

Specialty contractors need to meet strict deadlines and tight budgets. These subcontractors must be very accurate in their bids for a project, else they run the risks of not being awarded the project, going over budget, or not meeting a deadline when awarded the project. They will either lose business in the future or lose money if they cannot meet timeline and budget expectations. Due to the tough competition, there was pressure to complete projects in a shorter amount of time at a lower cost. For the subcontractor to earn a profit on a project, they had to understand their cost structure, including their labor costs, which was typically $30 \%-40 \%$ of their total costs and the single largest and most variable expense.

The industry used various options to track their employees' time and attendance (T\&A), ranging from a manual sign-in sheet to automated processes integrated into their payroll and accounting software. As with any procedure, the more manual it was, the less accurate and prone to errors.

Specialty contractors have to assess and monitor employee productivity to meet their deadlines and stay within their budgets. In construction, the firms must address multiple construction sites that are unique with different systems at each location and have varying processes for tracking their hourly workforce.

\section{Technology Impact}

New software applications improved a contractor's accuracy in the bid proposal, managed the project, and offered more efficient time and attendance tracking. Companies that leveraged new technologies, such as inventory and labor tracking software, had an advantage over those companies that resisted adopting new software applications by reducing costs and generating more accurate estimates.

The addition of mobile technology had significant impacts on how concrete contractors conducted business. Over $80 \%$ of construction professionals surveyed said that mobile technology is a high priority, and that 4 out of 5 are currently using some form of mobile technology (Novotny, 2019). The technology made manual timecards obsolete.

There were several benefits to an electronic time and attendance process that included lower labor costs compared against manual time tracking methods, decreased payment errors, improved controls for fraud, 
and better allocation to projects. A firm reduced labor costs associated with the time it took payroll clerks to manually enter data from timecards into the payroll system for each site. With more efficient ways to sign in rather than waiting in long lines to do so manually, firms decreased their labor costs. Simply by allowing employees to sign in at their work areas vs waiting in line at the job trailer could save an estimated 15 to 20 minutes per day or approximately $2 \%$ of payroll. With more controls around clocking in, a company prevented fraudulent activities, such as clocking in for friends.

Automated T\&A systems allow for the firms to add value to their customers by enabling better job costing for each construction site. Automated processes saved on paper costs and the storage of the paper timesheets.

\section{Company Overview}

MAVNS Concrete Construction, LLC was a company who, over the course of the last 100 years, had earned a reputation as an innovative industry leader in concrete construction. They served as a designassist structural concrete contractor that actively collaborated with several industry partners to identify better ways to build smarter, high performance structures (see Exhibit 3). These structures were buildings that incorporated higher performing structural systems, longer life cycles, and innovative energy savings that could be "built for less."

MAVNS experienced humble beginnings as the byproduct of a revolutionary idea and a dream of growth of one man - 26-year-old mechanical engineer C. Louis Meyer - back in 1912. Originating in Omaha, Nebraska, MAVNS initially began as a sales agent for fabricated reinforcing bar and clay tile used in the construction of reinforced concrete buildings. Meyer eventually developed a new construction system that emphasized the use of reusable steel forms that would replace the traditional wood and tile mediums used in many buildings at the time.

The Meyer Steelform construction system, as it came to be known, ultimately paved the way for the birth of MAVNS. This system garnered the attention of various architects and owners, and eventually brought in construction contracts. The first successful decade gave way to MAVNS opening offices around the country, developing new product lines, diversifying product offerings, and creating more jobs.

As time progressed, MAVNS drove reinvention and innovation throughout each decade. This included becoming one of the nation's lead wartime production companies of the 1940s, rapid expansion in the 1950 s, growth through acquisitions in the 1960s, divesting itself from its door products and preengineered metal building acquisitions in the 1990s, and focusing on strengthening its reputation as the leader in concrete formwork services and as an innovator of safety systems for the concrete construction industry through present day. Exhibit 4 presents MAVNS revenue from 2014-2019. Company offices are presented in Exhibit 5.

\section{Business Model}

MAVNS's goal was to lead the construction industry in the delivery of innovative client-focused structural solutions that provide exceptional results. Their national resources and local presence provided support from schematic design through top-out (pouring of the roof) of cast-in-place concrete structures. With MAVNS as the concrete contractor on site, general contractors and developers had a dependable design partner that could provide a firm schedule at a known cost and back it up in the field.

MAVNS's primary goal was to help its clients, owners, and end-users build the highest-performing structures possible with the least amount of initial and operational cost in the shortest amount of time. 
Some advantages of cast in place concrete construction are reduced lead time to start vs pre-cast or steel that requires months of pre-fabrication costs, and minimal maintenance costs due to the connections being encased in concrete and not exposed to the elements. MAVNS constantly strived to be a resource for its clients and industry partners, providing free input on approach, formwork system selection, shoring system selection, sustainability advice and structural system selection. Their input was distilled from more than 100 years of concrete experience which allowed them to serve as the ultimate construction consultant. They would always provide the resources necessary to make an informed decision on a client's project — whether they remained involved in the project or not.

MAVNS's local presence provided customers with convenient immediate access to a nationwide network of resources that could be applied to any region or project at any time. With extensive national engineering, formwork manufacturing and field resources at a customer's disposal, building possibilities were endless anywhere, anytime.

\section{Why MAVNS Versus Anyone Else?}

MAVNS would always suggest using a Choosing By Advantages (CBA) format to choose a project's structural system and would always include a sample among their resources for potential client review. CBA format is often used in construction; it provides methods to improve the decision-making effectiveness by providing transparency, explaining alternatives, evaluating cost data, defining factors, and connecting values.. Their thought process was that every project deserved a thorough analysis that accounts for all items affected by each different structural system.

MAVNS utilized a multifaceted approach to each client project that allowed them to build a customtailored process for completion. They knew that their list of strengths would give competitors a run for their money:

- Detailed preliminary estimates to establish budgets and help design the project cost-effectively.

- Commitment to a schedule upfront and that was upheld throughout the job, driving the rest of the subcontractors.

- Top-notch quality workmanship that was paired with a top-notch safety program.

- An eye for quality and innovation which solidified them as a leader in the concrete construction industry.

- Competitive construction market with fast-paced schedules and tight profit margins

- Offered more than a century of insight and experience to client project's constructability review and structural system selection.

- "Free-con" services to clients that would result in cost savings, even if MAVNS was not selected as the company to complete the construction.

\section{MAVNS At Their Core}

MAVNS would strive to identify better ways to build high-performance living structures and would actively engage their industry partners to take a holistic approach in doing so. At the core of their business was a desire to significantly decrease initial and operational costs and provide a better life cycle outcome for owners. As the nation's leading design-assist structural concrete contractor, MAVNS strongly believed in identifying the best possible outcome for its clients and partners and aimed to provide them with quality objective information regarding their project. The foundation of every project was represented by a guarantee of the safety, wellbeing, and development of MAVNS's employees; teamwork; integrity and ethics; an entrepreneurial spirit; innovation; openness, honesty, and respect; and the fulfillment of all commitments. 


\section{Evolving Past Paper}

Moving away from a paper payroll process was not a new project; Max first introduced the concept back in 1992. At the time, he could not get any buy-in from the jobsite Superintendents. He later brought back this idea in the early 2000s to no success. Max thought he had the momentum he needed when we pushed for a paperless system in 2013. In fact, he was able to get an office to test some technology that worked well, but the company Max was partnering with changed their sales model to software as a service (SAAS) which became cost prohibitive due to the number of employees and the fees assessed on a peremployee basis.

MAVNS relied on paper sign-in sheets as their time-keeping records for all job sites across the US. This method has been time-consuming and inefficient. The paper sign-in method required employees to wait in long lines to sign in or sign out of the job site. Information was then manually entered into spreadsheets that were then transmitted to payroll software. MAVNS stated that though this method was perfected over time, field supervisors still need to be tied to their computers. MAVNS has been unable to get an understanding of actual hours worked until the following work week.

MAVNS has 40-100 employees onsite for a typical project. Integrated new technology for onsite employees could improve their accuracy of tracking hours, cost codes, and employee's exact location.

\section{Electronic Time Keeping}

Electronic timecards provided an easy and accurate way to account for employee time, promoting timesavings by automatically integrating hours for payroll. The integration process eliminated data entry errors and helped streamline payroll operations while being accurate and compliant with labor laws and the Department of Economic Opportunity regulation.

This technology also assisted management with detailed information on employee overtime, length of employee breaks, and daily reporting of time. This software allowed managers to access reports and breakdown components of the data. Managers were able to set alerts for different categories, such as when an employee reached overtime.

There were many options to electronic timekeeping for the employee's log-in and log-out process. These options were website log-in, smart phones, magnetic cards, badges, PINS, or biometric recognition through biometric scanners. A badge is worn by the employee and used in a badge reader. Badges have the capability to have geolocation technology in the components. PIN numbers work with employees keying in a pin code that is prechosen for their identity. Smart phones give employees easy access to login-in or log-out of shifts and the options to manually switch between job tasks to account for job cost codes.

Murray recognized the benefits electronic timekeeping would add to the business, but he was very concerned about how the change would impact the team. The topic had been approached several times before, and the idea could not be moved forward due to the various complications it added. The software had to integrate with their accounting software, and their IT team didn't have time to devote to a largescale implementation. The crew leaders felt headquarters would micromanage them if the data were reviewed independently by the finance team. The technology at jobsites to capture the log-ins could be a source of friction when the software had issues. Murray knew the teams would be concerned with the 
time it would take to train the team to learn the new software and log-in/log-out procedures. The company needed to minimize the impact of the change on the crew leaders and their crews.

\section{Biometric scanners}

Biometric characteristics are unique characteristics of each person. These characteristics include fingerprints, facial images, iris, and voice recognition.

A biometric device was a security identification and authentication device. These devices would use automated methods of verifying or recognizing the identity of a person based on a physiological or behavioral characteristic. Biometric devices would be programmed with different software and certain biometric scanners.

A benefit of biometric characteristics scan during the clock-in process was the accuracy of the employee clocking in. This process eliminated time theft and buddy punching practices. Buddy punching was when a coworker would clock-in or clock-out a different coworker to show inaccurate unworked hours for the person who did not actually clock-in or clock-out. Another benefit was providing a level of security within a job location. Biometric scanners would limit access to specific locations based on an employee's preset corporate permissions. Biometric scanners would also assist during the new employee onboarding process to better identify the person you hired. This would improve the I9 and background screening process for potential employee candidates or newly hired staff.

\section{Geolocation and Geofencing}

Geolocation tracking enabled employers to track employee location and movement in real-time. Geolocation would track the location where an employee clocks-in or clocks-out and could be set to track each movement. This technology made it easier to monitor an employee's location. See Exhibit 6 for an illustration.

There were many benefits in tracking employee's location in real-time. Exact location measures could help provide better insight into labor costs for jobs. Many employees may work in different labor cost codes in the same day, this technology will quickly allow employee to switch between these different locations and different cost codes. Location tracking held employees more accountable for location and time of clock-in. During an emergency, a manager or crew leader could quickly account for their staff or easily pinpoint their location.

Geolocation tracking captured miles driven in company-owned or personal vehicles. Geolocation technology was also used to track company assets and property (Dunning, 2019). Florida law states companies had to receive consent from their employee before establishing geolocation tracking on their sign-in devices.

Geofencing was described as a geographical location within a specific boundary or invisible perimeter (Dunning, 2019). An exact detailed location was gathered by GPS satellites that pinpoint coordinates. Geofencing technology allowed an employer to set up boundaries within a specific site that prevented employees to sign-in without being within those boundaries.

\section{Radio Frequency Identification}

Radio Frequency Identification (RFID) was a form of wireless communication that used radio waves to identify and track objects (Bittle, 2020). 
RFID worked in three sections: endpoints, connectivity, and software.

- Endpoints - an item and its attached RAIN RFID tag chip radio that uniquely identifies the item.

- Connectivity - devices that enable wireless, bi-directional communication with endpoints.

- Software - aggregates and transforms data from endpoint reads, delivering real-time information to enterprise and consumer applications.

RFID technology would track when employees washed their hands or used hand sanitizer by synching with RFID technology tagged at hand sanitizer locations with the employee's geolocation tracking device. RFID would speed up the sign in process for employees as they would be tracked based on the location. This tracking would also help identify cost codes for specific areas that the employee worked.

\section{Implementation}

Electronic time keeping, biometric scanners and geolocation technologies helped all business, large or small. These technologies would increase productivity, accuracy and run locations more effectively and efficiently. There were different software options for Murray to choose. Murray could purchase an existing software as-is, purchase existing software and tailor the software to MAVNS's specific needs, or MAVNS could develop a software internally. After the software was established, MAVNS then had to decide if they wanted to utilize the software through badges, pin, website, smart phone, iPad, or keypad. MAVNS used iPads with most projects and on most job sites.

Implementing a new technology was challenging. MAVNS could implement a pilot program at certain job site locations to work out any problems before implementing it across the country. MAVNS also needed to have dedicated training staff to assist during the implementation process. To help make the implementation successful, MAVNS needed to include employees in the decision and inform them how this technology would benefit them directly. MAVNS should also listen to the feedback and concerns of its employees. MAVNS needed to receive buy-in from their employees to help drive these changes forward. MAVNS needed to consider all stakeholders when implementing new technology.

\section{MAVNS Moving Ahead}

\section{Cost Codes}

MAVNS used numerous cost codes to track the costs separately for every project, these line items cover everything from labor, to concrete, and rebar material. MAVNS tracked employee hours into different cost codes depending on what type of task they are working on. Examples of cost code descriptions are Foundations, Slab on Grade, Columns, Walls, Elevated Slabs, etc. Payroll was coded to these cost codes, and this information ties to their labor tracking program. On a weekly basis, this tracking program allowed them to see exactly how they were doing vs. an estimate for each of the tasks. For example, if payroll reported 540 hours to the Elevated Slabs cost code, it would show the estimated hours based on what they completed, say 560 hours, and show a pickup of 20 hours that week for Elevated Slabs. This information was used to manage the current projects budget as well as aid in estimating future projects. One issue with paper sign-in sheets was the accuracy of the recorded cost code. There was not a simple way to split daily activities into multiple cost codes if they switched tasks.

Electronic time keeping achieved more accurate reporting of hours to the appropriate cost code. Each employee would sign in with their crew leader, who would automatically assign the employee the correct cost code. The employee would have the ability to sign out from his current crew leader's workstation 
and sign into a new crew leaders' workstation. This would allow for their time to automatically be recorded to the correct cost code. While this may not seem like a complicated issue, Max recalls regional managers complaining, particularly in non-union markets, about the difficulty of recording and coding employee's time accurately. In fact, more than once a manager questioned why we even try to track the costs into separate cost codes because they do not trust the accuracy of the reporting. Max was certain an electronic time keeping system would improve the accuracy of coding time correctly as well as give reliable historical information for estimating and establishing future budgets.

\section{Crew Leaders}

A project's onsite field management typically consists of a job superintendent, an assistant superintendent, and a crew leader for every 10 employees. Each of these crew leaders were responsible for managing their hours and staying within the project's budget. With paper sign-in sheets, the crew leaders identify their employee's times, add them up and track them daily against the budget. The hours were posted in MAVNS's labor tracker every week, so manual calculations were the only way to obtain more accurate information. Most crew leaders do not have the time to do these calculations accurately, so the management of this suffers, leading to missed budgets. MAVNS has generally been on the cutting edge of technology as its labor tracker was first introduced over 20 years ago. Max wondered why it has taken so long to move away from paper sign-in sheets, but that is typical for the concrete industry. He thought we really had an opportunity to get an advantage if we managed this correctly.

Electronic time keeping allowed the crew leaders to identify all the hours worked in their area instantly at the end of the day by pulling up the software. Max knew this was key for better time management, setting goals, and ultimately saving MAVNS money. Another benefit of electronic time keeping was the employee would be able to sign in at their workstation if each Crew leader had an iPad. This would further save MAVNS time as employees were dismissed from work on an upper level and take their time to get back to the job trailer where they sign out on a paper sign-in sheet.

\section{Fraudulent Sign Ins}

Max was certainly aware of the concerns by regional managers and operation managers of the potential for employees to abuse the current system. MAVNS conducted audits on projects a few times a year on payroll and the sign-in sheets. It had been found that employees were signed in but no longer on the jobsite. The concern was that this employee may have one of his coworkers sign him out when they sign out later in the day. The common excuse was the employee had to leave early and forgot to sign out. Max did not believe this was a rampant problem, but none the less a concern where paper sign-in sheets fail. If he could only find an electronic time-keeping solution that would prevent others from signing in or out for another person, this would solve this problem and put some of the managers at ease.

\section{MAVNS Growth}

MAVNS had been growing its scope over the last decade and moving from supplying formwork only solutions to its customers to now providing a more comprehensive concrete structure package. Formwork only refers to the carpentry work needed to pour concrete on or in, sometimes referred to as falsework as this temporary structure was removed after the concrete had reached strength and could support itself. A formwork-only package to a customer supplies the material and labor to install the formwork, while MAVNS's customer, the General Contractor, manages other subcontractors that would install the reinforcing and pour the concrete. A formwork only package was more common in union markets and requires a lot less labor onsite, 12-20 employees. On the other hand, a turn-key project would have 40-80 employees. Max knew the industry was moving towards turn-key solutions with that scope making up approximately $60 \%$ of MAVNS's revenue, where only 15 years ago, MAVNS's scope was $100 \%$ 
formwork only. This change in scope meant MAVNS 's labor costs per project would continue to grow, and this time keeping problem would only get worse; Max knew there is no more time to wait.

\section{Going Paperless}

With the advancement of computer-aided design (CAD) and 3D modeling with software such as REVIT and TEKLA, drawings could be turned out a lot faster than in MAVNS's beginnings when all drawings were done by hand. A side effect of this fast flow of information was that owner's and architects can change the design of a building as it was getting built, as well as proceed with construction while some of the details were still being worked out. While this is great for the owner, it makes processing the additional information and changes difficult to manage for the builder. Paper structural, architectural, and formwork drawings were all printed on paper and could be found in the job trailer and copies with various crew leaders on the project. As these changes to the drawings happened faster and more frequently, MAVNS was forced to find a better way to make sure employees in the field had the latest information. Using cloud storage for managing current drawings, crew leaders were given iPads to access these drawings assuring they had the most current set of contract documents. MAVNS was now equipped with iPads being used in the field.

\section{$5^{\text {th }}$ Time's a Charm?}

After initially attempting to move away from paper payroll in 1992, then in the early 2000s and again in 2013, Max still believed MAVNS needed to make this leap in technology. Since MAVNS was ahead of the industry in safety, formwork systems, and other technology, Max made a deal, that may have involved an undisclosed amount of beer, with the head of IT, and they worked on their own time to develop their own software. After about a year with only a prototype to show for it, he realized a fully functional program was years away from implementation, and he was not even sure if anyone would use it. With this latest realization Max paused the work on developing the software in house to focus on the rebound MAVNS was seeing in construction since the recession. Max wondered if MAVNS would ever get away from paper.

\section{The Decision}

Being aware of the complexity of this issue, Murray knew that the time came to decide. Countless complaints from regional managers floating around in his psyche, only to intertwine with the amount of difficulty the company experienced with the accuracy of employee records and time coding. Technology had made the manual timecard obsolete, and the need for a tailormade solution for MAVNS's unique business needs became inevitable. The company depended on Murray to lead the way.

Despite not having unlimited resources, Murray's optimism persisted, knowing the business became more profitable with the addition of adequate technology and the significant impact it had on how his company did conduct business. Failing to adopt new innovative software would almost certainly cause Murray to lose the stronghold it had gradually gained on the market, and a large amount of leverage it had secured with customers and suppliers alike. Either way, this decision was critical and would warrant an investment, making immediate returns achievable in more forms than just risk reduction and cool, modern technology. What would be the most efficient and impactful way to accurately track, record, and code employee labor?

The options were:

1.) Continued to use paper sign in procedures, in order to save capital and not force change onto employees and crew leaders. 
Pros: a. Not disrupting the workforce, especially in this COVID environment, to push a change upon them.

b. Another pro to consider was that the projects that were in locations where the workforce were members of a union. We needed to consider the impact on changing the process of logging in and out on the actual jobsite vs the trailer.

Cons: a. This delays the cost savings we will realize by changing our T\&A system which is critical during this COVID time period.

b. Accrued time spent by workers waiting in line to sign in on paper will carry over as unnecessary cost.

2.) Implement electronic badge timecards using a 'ready out of the box' software application for the team members to swipe in and out at the trailer to account for employee time keeping that's integrated with their payroll software. The implementation would be rolled out in three phases with the first phase focusing on the states where we have the highest productive crews as the priority. The idea would be to get feedback and lessons learned from the engaged management teams that could be rolled into future implementation plans.

Pros: a. We roll this out to a highly engaged team and evaluate the impact. Pending the success, this "pilot team" can help secure buy-in from the other management teams on a broader scale.

b. By keeping the time log process at the trailer, impact to the crews is minimized while additional benefits of using an automated T\&A are realized.

Cons: a. By rolling this out in three phases, we may not get enough momentum to implement it across all locations in a timely manner.

b. We may not get the buy in from the other managers even if we are successful with the first phase.

3.) Develop their own time-keeping software utilizing existing iPads with the use of biometric scanners to have each employee sign in with their crew leader at specific job site locations. The expected savings from using an internal time-keeping application and current iPads could be used to incentivize the middle management team for their engagement on the implementation.

Pros: a. By using existing iPads, capital can be saved and reinvested into other resources that will continue to build competitive advantages within MAVNS.

b. By creating our own software, it can be customized to meet our specific needs and update as necessary with minimal downtime.

c. Money saved and customization ability will be attractive for middle management buyin. As such, chances of $100 \%$ implementation and speed of execution should be high. Push back should be minimal.

Cons: a. Developing software internally may take a long time and integrating the iPads and the payroll software may be challenging.

b. Incentivizing middle management for software implementation is not a great model to establish for implementing new technology and may not be sustainable.

c. Developing software internally would also require additional resources for checks and balances as it relates to the accuracy of the system. Any raised discrepancies would need to be systematically dealt with to avoid larger issues or potential HR claims. 
4.) Partner with a vendor to customize a solution that allows for multiple sign-in methods including geolocation and geofencing, giving the company the ability to locate and track the movement of employees in real time. The vendor will be acting as a project manager as well as a change manager to engage the employees and leaders. The change managers will work on an education initiative to communicate the benefits of the conversion to electronic T\&A for the health of the company, especially in a competitive market and during the COVID pandemic.

Pros: a. We can adopt multiple sign-in methods for the different locations that are more custom tailored to site specific needs.

b. By partnering with a vendor, we will benefit from value added project management and change management services; both are needed to ensure large scale buy-in and successful implementation.

Cons: a. The cost of partnering with a vendor to customize a solution will be the largest capital investment. However, an ROI needs to be completed to understand the labor cost savings of implementing an automated T\&A needed to offset the additional capital for this option.

b. It is challenging to use vendors and consultants to get employee buy-in even with a change manager; one way to combat this is for the change manager to train/educate internal teams and then, have the internal teams start a 'grass roots' type of movement to get buy-in.

c. Allowing multiple sign-in methods may not reduce the time necessary to complete the process at each site. As a result, time related costs are still incurred and passed on to the clients.

Max reached out to his team, reluctantly scheduling their next meeting under the presumption that he had to make his next move his best move, as profitability hung in the balance. These options would be presented to the executive team with the potential of each option extensively explained; MAVNS was about to enter the final frontier.

\section{References}

Ridell, T. (2017). What Makes a Specialty Contractor So Special? Retrieved from https://esub.com/makes-specialty-contractor-special/

IBIS World (2020). Concrete Contractors Industry in the US-Market Research Report. Retrieved from https://www.ibisworld.com/united-states/market-research-reports/concrete-contractors-industry/

Novotny, R (2019). How Mobile Technologies Connect Field Office with Integrated Labor Delivery. Retrieved from https://esub.com/mobile-technology-transforming-construction-industry/

Dunning, K. (2019.) Employee Geofencing: How Does it Work? Retrieved from https://blog.boomr.com/employee-geofencing/

Bittle (2020). Your Boss Wants to Know Whether You Washed Your Hands Retrieved from https://slate.com/technology/2020/05/rfid-technology-handwashing-social- distancingcoronavirus-workplace.html 


\section{Biographies}

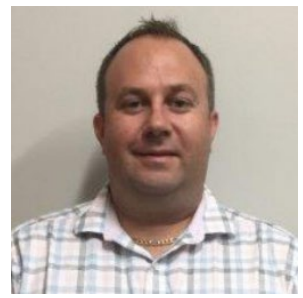

Chad Anast is a Regional Manager in the construction industry over seeing offices in the Southeast United States. He is a graduate from the University of Florida with Bachelor Degrees in Civil Engineering and Architecture and Master's Degree in Architecture and is currently enrolled in USF's EMBA program.

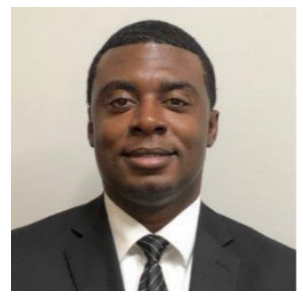

Michael McClendon II is a Design Engineer at Pierce Manufacturing in Bradenton, Florida and has been since 2015. Prior to coming to Pierce, he served as a cannoneer with the US Army at Fort Hood. McClendon earned a bachelor's Degree in Engineering Technology from Daytona State College (2018) and is currently completing his Executive MBA at the University of South Florida.

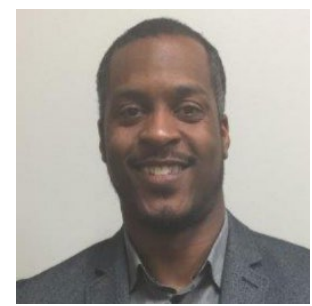

Russell Nelson is a Program Execution Manager at Coca-Cola Beverages Florida. $\mathrm{He}$ is a graduate from Morehouse College in Atlanta with a bachelor's Degree in Business Marketing and is currently enrolled in USF's EMBA program.

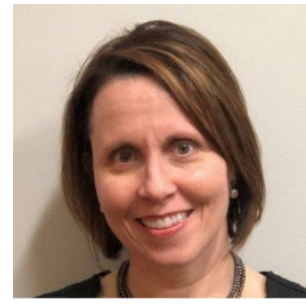

Melissa Smith is a Department Administrator in the Malignant Hematology Program at Moffitt Cancer Center. She is a graduate from Florida State University with a bachelor's Degree in Accounting. She is currently enrolled in USF's EMBA program.

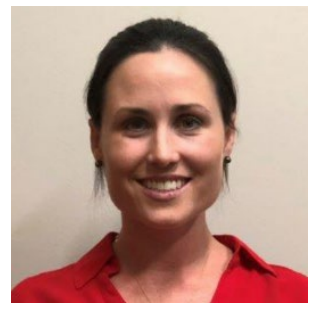

Stacie Varney is the co-owner of Next Ride with two motorcycle dealership locations in Florida. She is a graduate of the University of South Florida with a bachelor's Degree in Psychology. She currently is enrolled in USF's EMBA program. 


\section{Exhibit 1: MAVNS Sign-In Sheet}

\begin{tabular}{|c|c|c|c|c|c|c|c|c|c|c|c|c|}
\hline \multicolumn{13}{|c|}{ Daily Attendance Log } \\
\hline \multicolumn{13}{|c|}{$\begin{array}{l}\text { English - By signing below I certify that I have accurately recorded my working time and that the required meal breakis) were taken or are recorded as missedinterrupted as authorized by my supervisor. I } \\
\text { understand that it is a serious violation of company policy to allow anyone else to sign in/out on my behalf. I have not been instructed to perform work or record hours that are not properly accounted for. I } \\
\text { further certify that any work injurylaccident was reported immediately to my supervisor. }\end{array}$} \\
\hline \multicolumn{13}{|c|}{$\begin{array}{l}\text { Spanish - Al firmar a continuación, certifico que he registrado con exactitud el tiempo de trabajo y que el descanso para comer requerida (s) se tomaron o se registran como perdidas / interrumpido según lo } \\
\text { autorizado por mi supervisor. Entiendo que se trata de una grave violación de la politica de empresa para permitir a cualquier persona acceder y salir en mi nombre. No he recibido instrucciones para llevar } \\
\text { a cabo las horas de trabajo o registro que no están debidamente contabilizados. Certifico, además, que cualquier lesión / accidente de trabajo fue reportado inmediatamente a mi supervisor. }\end{array}$} \\
\hline \multirow[b]{2}{*}{$\begin{array}{c}\text { Name } \\
\text { Nombre }\end{array}$} & \multirow[b]{2}{*}{ Emp. ID } & \multirow[b]{2}{*}{$\begin{array}{l}\text { Absence } \\
\text { Ausento }\end{array}$} & \multirow[b]{2}{*}{$\begin{array}{l}\text { Sign In } \\
\text { Firma }\end{array}$} & \multirow[b]{2}{*}{\begin{tabular}{c|c} 
Time In \\
Tiempo de \\
Entrada
\end{tabular}} & \multirow[b]{2}{*}{$\begin{array}{l}\text { Sign Out } \\
\text { Firma }\end{array}$} & \multirow[b]{2}{*}{\begin{tabular}{|c|c|c|}
$\begin{array}{c}\text { Time Out } \\
\text { Tiempo de } \\
\text { Salida }\end{array}$ \\
\end{tabular}} & \multirow[b]{2}{*}{\begin{tabular}{l|l} 
Hours \\
Horas
\end{tabular}} & \multirow{2}{*}{$\begin{array}{l}\text { MeallComida } \\
\text { (30 minute / minutos } \\
\text { minimum / minimo) } \\
\mathrm{Y} / \mathrm{N} \text { / Si / No }\end{array}$} & \multicolumn{2}{|c|}{$\begin{array}{l}\text { Sick TimerTiempo } \\
\text { por Enfermedad }\end{array}$} & \multicolumn{2}{|c|}{ Injury/Lesión? } \\
\hline & & & & & & & & & \begin{tabular}{|l|} 
por En \\
Hours \\
Horas \\
\end{tabular} & \begin{tabular}{|l|} 
nfermedad \\
Date Fecha
\end{tabular} & \begin{tabular}{|l|}
$\mathrm{Y} / \mathrm{N}$ \\
Si/No \\
\end{tabular} & $\begin{array}{l}\text { Supenisor notified? Y/N } \\
\text { Supervisor notificado? SilN }\end{array}$ \\
\hline & & & & & & & & & & & & \\
\hline & & & & & & & & & & & & \\
\hline & & & & & & & & & & & & \\
\hline & & & & & & & & & & & & \\
\hline & & & & & & & & & & & & \\
\hline & & & & & & & & & & & & \\
\hline & & & & & & & & & & & & \\
\hline & & & & & & & & & & & & \\
\hline & & & & & & & & & & & & \\
\hline & & & & & & & & & & & & \\
\hline & & & & & & & & & & & & \\
\hline & & & & & & & & & & & & \\
\hline & & & & & & & & & & & & \\
\hline & & & & & & & & & & & & \\
\hline & & & & & & & & & & & & \\
\hline & & & & & & & & & & & & \\
\hline & & & & & & & & & & & & \\
\hline & & & & & & & & & & & & \\
\hline & & & & & & & & & & & & \\
\hline
\end{tabular}

Source: Developed by case writer 


\section{Exhibit 2: Number of Employees of Last 5 Years}

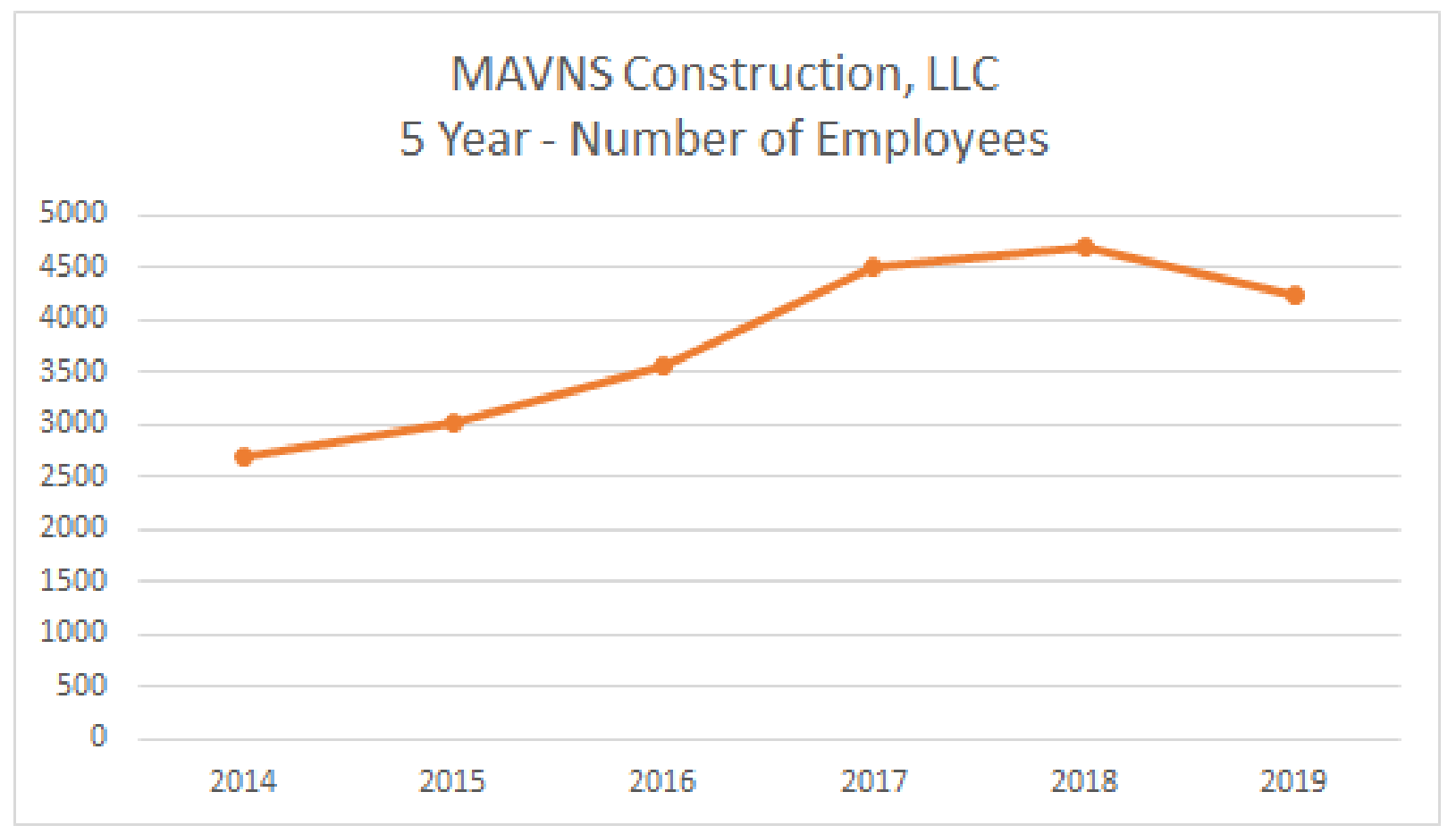

Source: Developed by case writer 


\section{Exhibit 3: Typical Commercial Concrete Projects Completed by} MAVNS
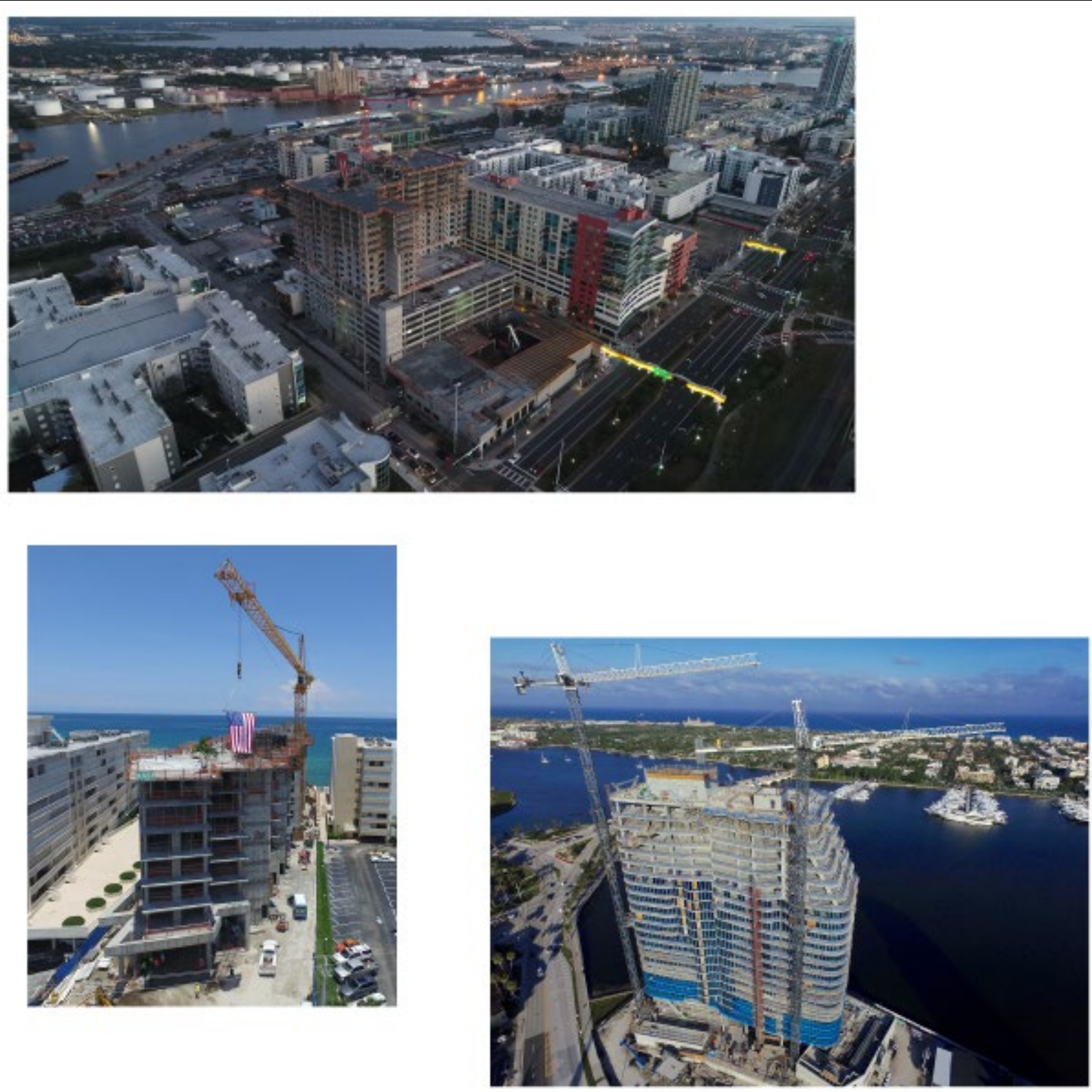

Source: Developed by case writer 


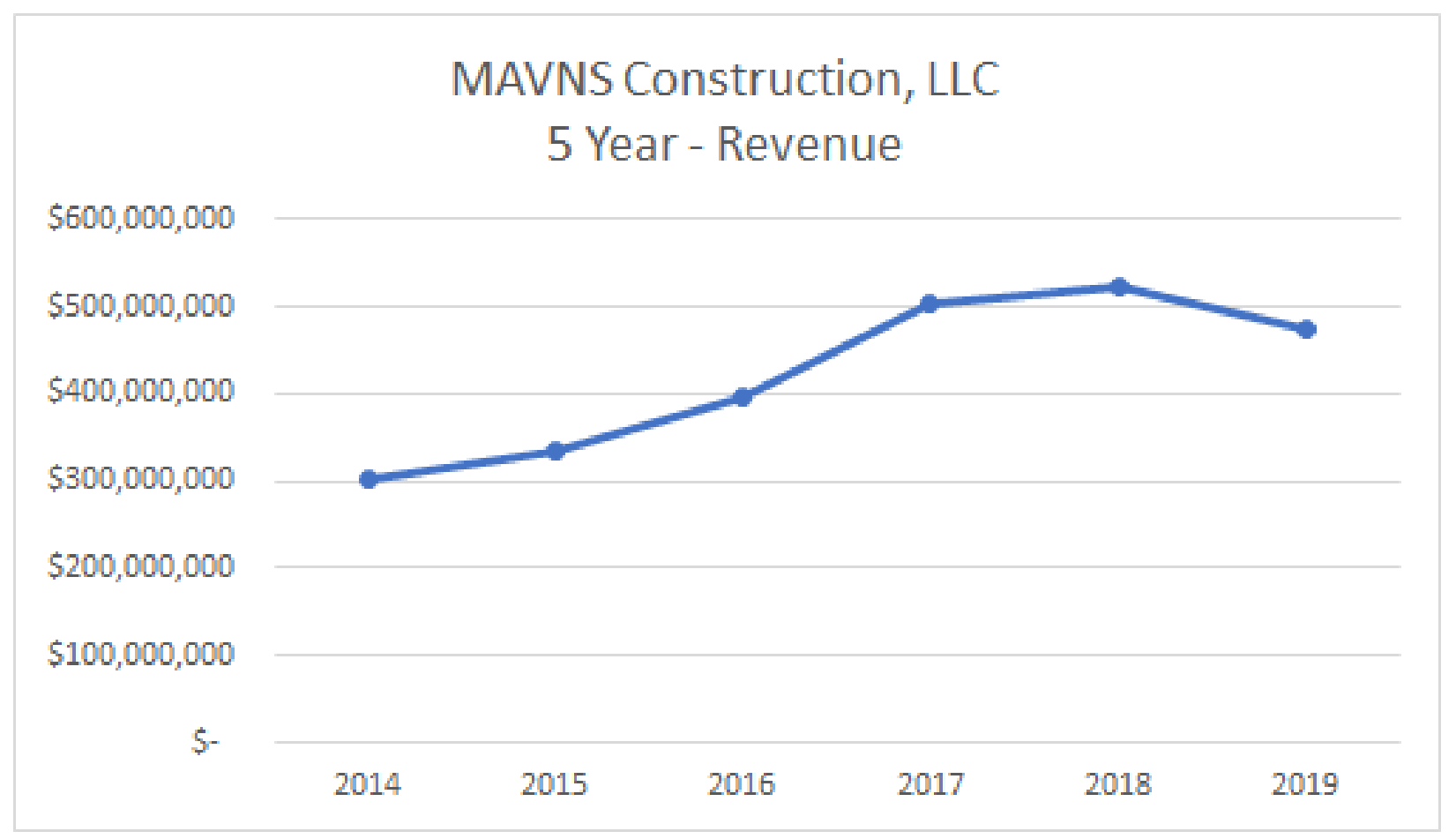




\section{Exhibit 5: MAVNS Office Locations}

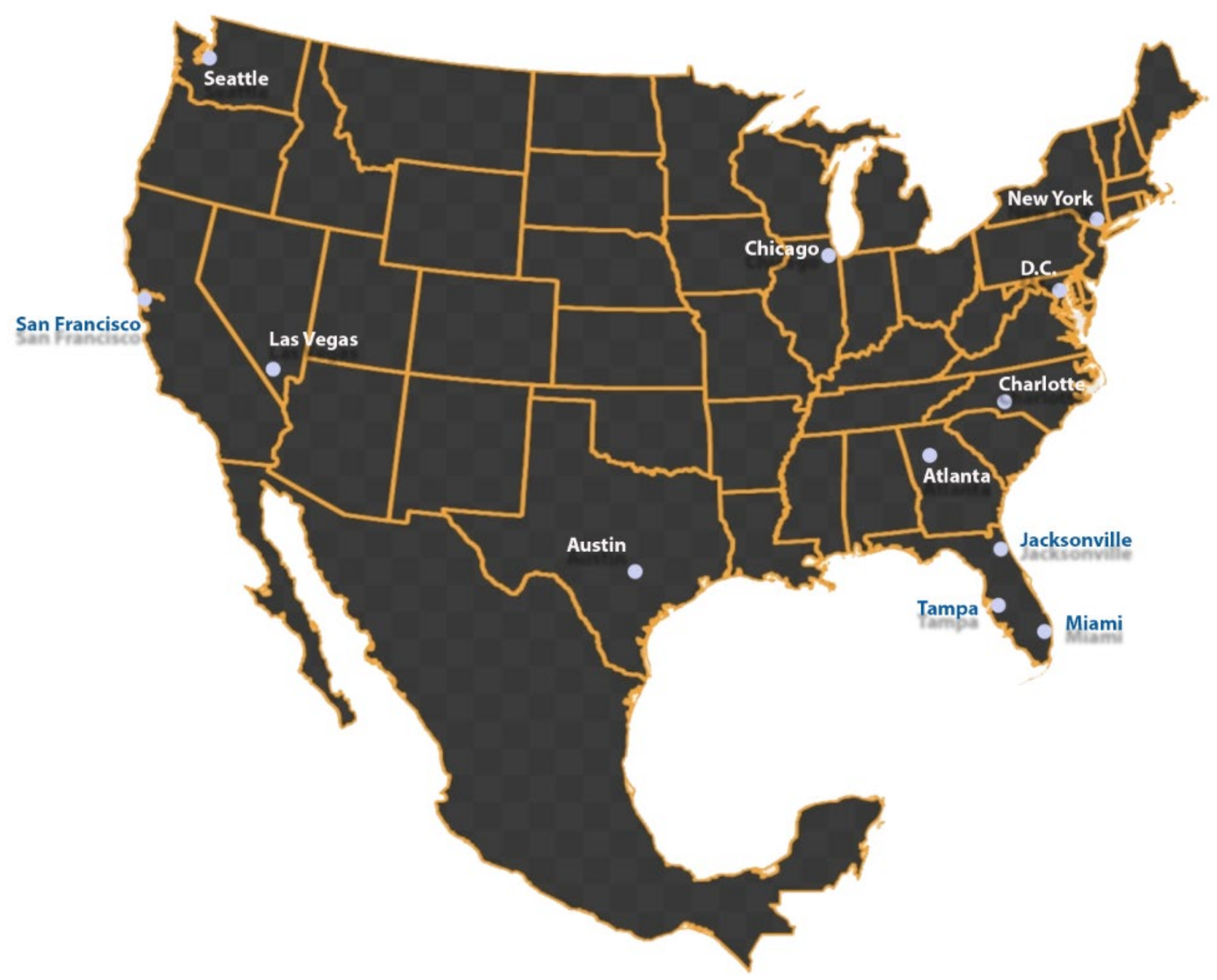

Source: Developed by case writer 


\section{Exhibit 6: Electronic Sign-in and Geolocation Technology Image}
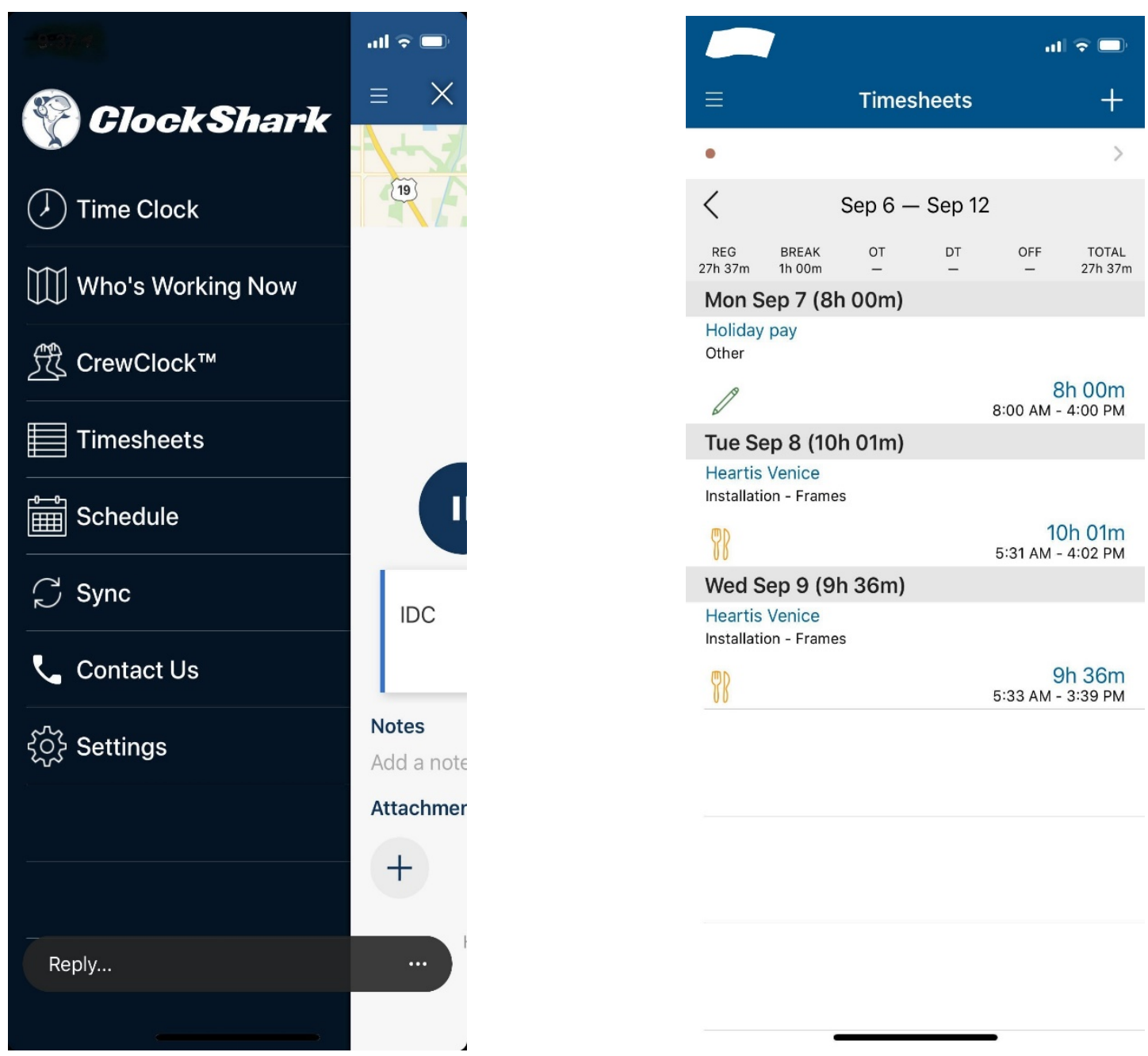

Source: Developed by case writer 
